\title{
$O$ desafio da interdisciplinaridade na Faculdade de Medicina do ABC
}

\section{The challenge of interdisciplinarity at Faculdade de Medicina do ABC}

\author{
Fernanda Castilho Leite ${ }^{1}$, Ricardo Lopes Correia² ${ }^{2}$ Teresa Cristina Brito Ruas \\ ${ }^{1}$ Curso de Terapia Ocupacional - Faculdade de Medicina do ABC (FMABC) - Santo André (SP), Brasil. \\ ${ }^{2}$ Departamento de Terapia Ocupacional, Faculdade de Medicina, Universidade Federal do Rio de Janeiro (UFRJ) - Rio de Janeiro (RJ), Brasil.
}

DOI: http://dx.doi.org/10.7322/abcshs.v40i3.818

\section{RESUMO}

Introdução: Vivemos a emergência de ações movidas interprofissionalmente, e caminhamos para superação da lógica multiprofissional fragmentada, para tanto, agenciamos maneiras para vivenciar as fronteiras criadas entre os distintos e necessários conhecimentos que demarcam a diversidade identitária de cada profissional. Diante dessa realidade, o presente estudo teve por objetivo discutir o posicionamento interdisciplinar da Faculdade de Medicina do ABC (FMABC) em suas ações de ensinagem, em atenção especial para o campo da extensão universitária. Relato de experiência: As práticas diárias de ensinagem na FMABC, guiadas pelo tripé ensino, pesquisa e extensão, têm nos mostrado como resultado que, de fato as experiências de extensão, sustentadas pela Saúde Coletiva, nos parecem ser um núcleo que permite uma dialogicidade de saberes e práticas num campo amplo como a saúde e a suas interfaces, uma vez que é sua essência ser um núcleo multiprofissional e interdisciplinar, pois se constitui como um paradigma da realidade e de interpretações e intervenções na saúde. Conclusão: Portanto, é justamente pela ação interdisciplinar que o ensino superior em saúde consegue preconizar o pensamento complexo e formar profissionais capazes de compreender que o saber e a prática de intervenção se fazem em uma produção de compreensões e acordos para a ação das mudanças das barreiras e dos determinantes que impedem a qualidade de vida da população e os efeitos dessa implicação na formação universitária.

Palavras-chave: relações comunidade-instituição; universidades; saúde pública.

\begin{abstract}
Introduction: We are currently witnessing the emergence of interprofessional actions and moving towards the overcoming of fragmented multi-professional logic and this requires that we work as agents of ways to acknowledge the boundaries created between distinct and necessary pieces of knowledge that delimit the identitier diversity of each professional. Therefore, the objective of this study was to discuss the interdisciplinary positioning related to teaching actions in Faculdade de Medicina do ABC (FMABC), with special attention to the graduate extension field. Experience report: Daily teaching practices in the FMABC, directed by the tripod teaching, research and extension, have shown us, as a result, that in fact the extension experiences guided by the Collective Health seem to be a core that enables a dialogicity of knowledge and practices in a widespread field as the health and its interfaces, since its essence is to be a multi-professional and multidisciplinary core, as it constitutes a paradigm of reality and interpretations and interventions in the health. Conclusion: That it is just through the interdisciplinary action that health superior teaching can manage to praise the complex thinking and to prepare professional people capable of understanding that the knowledge and practice of the intervention take place in a production of understandings and agreements for actions that change the barriers and determiners that impair the population life quality as well as its effects on university graduates.
\end{abstract}

Keywords: community-institutional relations; universities; public health. 


\section{INTRODUÇÃO}

\section{Um panorama sobre o modelo hegemônico de ensino: caminhos trilhados e percursos possíveis}

Desde a consolidação do modelo positivista enquanto paradigma científico, os modelos de estudo e de ensino nos ensinam a separar e olhar as partes, e ao longo da história fomos nos tornando quase que incapazes de perceber as relações entre elas e, com isso, as disciplinas se tornam módulos de pesquisa, centradas nelas mesmas, e gerando respostas para elas mesmas.

O conhecimento científico também foi durante muito tempo, e com frequência, ainda continua sendo concebido como tendo por missão, dissipar a aparente complexidade dos fenômenos a fim de revelar a ordem simples a que elas obedecem. Mas se resulta que os modos simplificadores de conhecimento mutilam mais do que exprimem as realidades ou os fenômenos de que tratam, torna-se evidente que eles produzem mais cegueira do que elucidação ${ }^{1}$.

As reflexões tecidas nesse estudo são guiadas pelos conhecimentos e teorias que questionam modelos de ensino e aprendizagem puramente empíricos, teorias redutoras, ou, até mesmo, modelos pré-definidos que fogem da lógica da compreensão do valor da historicidade, da cultura e do contexto social nas diversas vivências e experiências de agentes envolvidos nos processos de apreender e ensinar a realidade. É como se, a partir da ótica dessas teorias mais questionadoras e "libertadoras", fosse mais claro percebermos as incoerências presentes em um modelo hegemônico de ensino que não reconhece as contribuições e complementariedades existentes entre as diferentes disciplinas que o constitui.

A divisão cartesiana, delimitando fronteiras entre as disciplinas, se dá desde o início da formação escolar até as universidades, que se organizam em faculdades e são divididas, a priori, em três grandes áreas: exatas, humanas e biológicas. No entanto, essas áreas não conseguem reconhecer os elos religantes que existem entre elas e, ainda, dividem-se em disciplinas, que entram em uma disputa de poder hegemônico, e não em uma lógica de colaboração e complementariedade dos saberes.

A formação superior na área da saúde está subsidiada por um discurso pedagógico que normatiza a relação de "poder" e "saber" diante do processo de saúde e doença.

Sabe-se que essa relação é transmitida com base em um saber positivista, organicista e biologizante que valida e trata a saúde como a ausência total de doença, de incapacidade e/ou de deficiência intrínseca e centrada no próprio indivíduo ${ }^{2,3}$. A doença ainda é vista como uma condição que gera um desequilíbrio, uma desarmonia e uma falta de produtividade na vida diária humana ${ }^{3}$. Assim, o olhar clínico, ensinado e aprendido, diante da relação de saúde e doença, ainda objetiva ver no homem o produto de seu corpo, negando a possibilidade de fazer dele e de sua saúde um produto de suas técnicas, modos de vida e de suas representações sociais ${ }^{2,4}$.
A própria condição de estar vivo e vivenciar diferentes experiências de saúde e/ou de doença não se encontram interligadas entre si e caracterizadas como um atributo próprio da condição humana. Ora, essa prática, aparentemente didática, de divisão é extremamente equivocada, se ela não recorre, imediatamente, à reorganização e (re)ligação das disciplinas, do conhecimento e das próprias experiências vividas.

Sendo todas as coisas causadas e causadoras, ajudadas e ajudantes, mediatas e imediatas, e todas elas mantidas por um elo natural e insensível, que interliga as mais distantes e as mais diferentes, considero impossível conhecer as partes sem conhecer o todo, assim como conhecer o todo sem conhecer particularmente, as partes ${ }^{5}$.

Diante da importância em compreendermos a relação dinâmica entre o todo e suas partes e vice-versa, os saberes interdisciplinares - como os da Saúde Coletiva (SC) que abarcam questões sociais e multifacetárias - deveriam ser direcionadores teóricos mais potentes em qualquer formação superior em saúde ${ }^{3}$.

A institucionalização dos saberes e sua organização em práticas se daria mediante a conformação de núcleos e campos. Núcleo como uma aglutinação de conhecimentos e como a conformação de um determinado padrão completo de compromisso com a produção de valores de uso. O Núcleo demarcaria a identidade de uma área de saber e de prática profissional; e o campo, um espaço de limites imprecisos onde cada disciplina e profissão buscariam em outros apoios para cumprir suas tarefas teóricas e práticas ${ }^{6}$.

Dessa forma, compreendemos que, para a formação em saúde, urgem ações interdisciplinares e multifacetadas entre as diversas disciplinas, que perpassam as especificidades desse campo com seus diversos núcleos profissionais e o diálogo e ação constantes com os campos das ciências humanas e exatas.

Se o processo ensino-aprendizagem está organizado de modo dicotômico, e não em "olhares e fazeres" interdisciplinares, a formação profissional também será dicotomizada. Isso dificulta o entendimento da necessidade de uma equipe integrada, já que só se olha para a sua especialidade e não a relaciona com as demais e suas interfaces, de forma integrada, com outros campos de fazeres e núcleos de práticas.

Vivemos num mundo globalizado, que torna, cada vez mais, os problemas e as soluções globais, portanto, o momento atual exige ações em saúde e em educação que também permeiem e interliguem as ciências biológicas às humanas e exatas. E quando pensamos na formação superior, nesse contexto, as especialidades e os saberes particulares de cada área de atuação são extremamente importantes para a constituição dos conhecimentos que caracterizam e diferenciam as profissões da saúde ${ }^{3}$. Porém, o profissional do século XXI precisa romper fronteiras teóricas e práticas e compreender que, para atender as diferentes demandas 
e necessidades apresentadas pela sociedade atual, são necessários olhares e práticas interdisciplinares e multifacetários, capazes de validar os diferentes tipos de conhecimento ${ }^{3}$.

A realidade profissional mostra que a prática em saúde exige, cada vez mais, que as relações interprofissionais extrapolem a lógica multiprofissional e as fronteiras criadas entre os distintos e necessários conhecimentos que demarcam a identidade de cada profissional. Aqui, como afirmado no parágrafo anterior, não defendemos que a identidade profissional seja extrapolada e, sim, que os diferentes profissionais compreendam os elos de união e de diálogo que existem entre eles. Principalmente, porque a demanda dos usuários, cada vez mais complexas, exige profissionais capazes de se organizar de modo interdisciplinar, capazes de olhar e analisar todo o contexto complexo do indivíduo, seu cotidiano e suas singularidades.

A incapacidade de conceber a complexidade da realidade antropossocial, em sua microdimensão (o ser individual) e em sua macrodimensão (o conjunto da humanidade), conduz a infinitas tragédias e nos conduz a uma tragédia suprema ${ }^{1}$.

A ação em saúde deve preconizar a organização dos serviços em rede e a relação interdisciplinar, que permitam uma leitura capaz de gerar ligações, como proposto por alguns estudiosos como Edgar Morin: "uma cabeça bem feita” significa:

em vez de acumular o saber, é mais importante dispor ao mesmo tempo de uma aptidão geral para colocar e tratar problemas e princípios organizadores que permitam ligar saberes e lhes dar sentido 5 .

A leitura "freireana" da realidade é geográfica, política, estética, ortopédica, psicológica, filológica e afetiva. ESTAMOS DIANTE DE UM MODO DE LEITURA QUE ARTICULA elementos de realidade que certa tradição ocidental teima em separar, dicotomizando. Nessa leitura ARTICULAM-SE subjetividade/objetividade, corporalidade/abstração, poesia/ciência ${ }^{7}$. (grifos do autor)

Se o educador entende a realidade complexa da organização social, e do próprio sujeito, também percebe que educar é mais do que ensinar conceitos e técnicas, conceitos são conseguidos no dicionário, técnicas são aprendidas em manuais técnicos. Mas o significado da relação entre sujeitos se aprende na própria relação, a aplicação dos conceitos e técnicas se aprende aplicando. Nesse sentido, as relações estabelecidas entre sujeitos em uma sala de aula determina a forma como os profissionais irão se relacionar com outras pessoas, profissionais ou usuários dos serviços, na sua prática profissional.

Não queremos com isso dizer que o papel do educador está em mostrar como se relacionar, ele vai dar conceitos e técnicas, mas ele vai ajudar o aluno a entender o sentido e o significado desses conceitos e dessas técnicas na relação com o outro, contextualizados, segundo as demandas atuais de nossa sociedade. Afinal, o aluno deve ser um ator social capaz de compreender, criticamente, o contexto e as demandas que caracterizam o seu dia-a-dia como profissional e cidadão.

Compreender a realidade complexa, como substrato da formação em saúde, exige uma imersão na historicidade daqueles agentes envolvidos no processo de apreender a realidade e apreender os modos de intervir. Isso significa:

[...] reconhecer o conhecimento como uma produção social, que resulta da ação e da reflexão, da curiosidade em constante movimento de procura ${ }^{7}$.

Com isso, o educador deve reconhecer a experiência do estudante como parte fundamental do processo de ensino e aprendizagem, além de ampliar a consciência sobre os elementos de sua própria historicidade, que permeia e qualifica suas estratégias de apreender e ensinar a realidade. Essa é uma das formas pelas quais poderemos compreender melhor as percepções dos alunos, para a partir daí propor novas formas de enxergar, de refletir e de lidar com as demandas apresentadas.

Nesse caminho de aprendizado e reflexões, o educador pretende mostrar outras possibilidades, mais contextualizadas às necessidades individuais e coletivas. Existem conceitos que dados pela ciência, mas é possível que cada sujeito entenda, perceba, signifique e dê sentido de acordo com as próprias experiências anteriores, e é aí que se dará a diferença da prática de cada profissional, não somente no sentido de procedimentos e técnicas, mas das relações.

O educador auxilia o aluno a perceber, criticamente, todo o seu entorno, subjetiva e objetivamente e, portanto, permite ter o seu discurso analisado, se coloca à disposição para discutir, e até mudar, porque reconhece que o processo pedagógico é de troca, e não de doutrinamento. Somente se abrindo para a experiência de troca e valorizando a experiência do outro é que o educador garante um processo pedagógico que faça sentido e que tenha significado para o aluno, e só assim ele pode conseguir formar profissionais críticos, e que façam uma leitura complexa da realidade.

Isso quer dizer que a qualidade da formação superior não pode responder somente às dimensões do aprender a fazer, mas também do aprender a aprender e do aprender a ser com uma implicação crítica, política, democrática e social para o melhor enfrentamento e compreensão teórico-prática das necessidades sociais e coletivas em saúde ${ }^{3}$.

A ação interdisciplinar nos leva a novas disciplinas, novas práticas, novos problemas. Daqui decorrem duas consequências importantes: o alargamento do conceito de ciência e a necessidade de reorganização das estruturas da aprendizagem das ciências, nomeadamente, a universidade ${ }^{8}$. 
Portanto, o desafio da interdisciplinaridade está dado, fazer a ligação entre saberes, até agora desconectados, e às vezes antagônicos, mas que, quando religados, ampliam a capacidade de percepção do sujeito, garantindo-lhe mais autonomia e mais capacidade de se entender numa rede de sujeitos e saberes diversos, que se sustentam nas ligações e sínteses, e não nas separações e análises.

\section{RELATO DE EXPERIÊNCIA}

\section{Os caminhos da ação interdisciplinar na Faculdade de Medicina do ABC: um campo de desafios ao status quo}

Só é possível pensarmos além das fronteiras profissionais se pensarmos além das fronteiras disciplinares, ou seja, só é possível pensarmos práticas intersetoriais, equipes interdisciplinares, se a interdisciplinaridade estiver na própria organização educacional. Se ainda vivemos uma organização sustentada pelos departamentos, precisamos pensar relações que aproximem os discursos, as práticas e reconheçam as interdependências, valorizando o trabalho conjunto.

Para a Faculdade de Medicina do ABC (FMABC) também há um grande desafio na busca dessas aproximações disciplinares e profissionais, até por uma questão histórica, que não se difere do desenvolvimento das estratégias de atenção à saúde, que nascem centradas na figura do médico, e conforme a própria organização social vai se modificando, as demandas vão se transformando e crescendo. Há o reconhecimento da necessidade de outros profissionais, que vão surgindo no mercado e, hoje, temos uma equipe ampliada de profissionais da saúde, a fim também de buscar um entendimento de toda a complexidade demandada das relações das comunidades com os serviços de saúde.

A FMABC nasce, enquanto Instituição de Ensino Superior (IES), com o curso de medicina, e ao longo desses mais de 45 anos de história, vem ampliando o seu quadro de formação, que em 2015 é formado por 8 cursos na área da saúde: Enfermagem, Farmácia, Fisioterapia, Gestão em Saúde Ambiental, Medicina, Nutrição, Terapia Ocupacional e, mais recentemente, Tecnologia em Gestão Hospitalar, que se complementam e se auxiliam na prática profissional cotidiana.

Nesse sentido, a FMABC já busca desenvolver essa consciência e ação interdisciplinar através de ações da extensão universitária, assumindo um compromisso com esse eixo educacional, indissociado do ensino e da pesquisa. Esse eixo se mostra potente, pois colabora para que estudantes e professores se aproximem das comunidades e da população com que trabalharão enquanto profissionais. Além, é claro, de permitir ao aluno o encontro e a inter-relação com outras práticas profissionais, que são específicas e características de cada profissão, mas que podem ser complementares entre si, garantindo um olhar ampliado e complexo diante das condições de vida e de saúde, da população à qual oferecemos assistência.
Entretanto, ainda é preciso descobrirmos os pontos de intersecção, através dos quais nos aproximamos, para entendermos a nossa rede de sujeitos e saberes diversos, mas complementares.

É preciso buscar modos de transformar as fronteiras existentes entre as disciplinas/profissões, para abri-las na direção umas das outras, buscando pontos de aproximação, que também são pontos de elucidação teórico-prática. Através das práticas de extensão universitária, a FMABC aciona estratégias de ensino, sob as perspectivas da SC e "atenta às experiências da ação comunicativa com as diversas realidades sociocomunitárias, possui como eixo estruturante a dialogicidade e interdisciplinaridade" ${ }^{9}$.

\section{DISCUSSÃo}

\section{A Saúde Coletiva e as estratégias de ensinagem na extensão universitária: pontos de intersecção para a formação em saúde}

O enfrentamento das barreiras que impedem a compreensão de um processo saúde-doença mais amplo do que a ideia médica-centrada nos aspectos clínico-sanitários e de ausência de doença são pontos relevantes para o núcleo da $\mathrm{SC}^{6}$.

Para o autor, a SC é inaugurada num marco do processo de democracia brasileira, de construção e garantia de direitos sociais e individuais, na qual podemos colocar o Sistema Único de Saúde (SUS) como uma das mais importantes expressões para a qualidade de vida e de direitos sociais da população.

A SC como um núcleo complexo de ubiquidade de saberes e práticas exige um posicionamento ético-técnico-político frente à realidade e aos agentes que a constroem, em oposição ao positivismo que reduz a apreensão das experiências entre saúde e doença e seus modos processuais de intervenção.

A complexidade atual do campo da saúde coletiva permeia tanto suas práticas como seus discursos disciplinares e suas formas de expressão acadêmicas, neles originando um conjunto de mediações de natureza, não apenas teóricas (entre disciplinas que compõe o campo), como política, social, e cultural $[\ldots]^{10}$.

Ora, a SC nos parece ser um núcleo que permite um dialogo de saberes e práticas num campo amplo como a saúde, uma vez que é sua essência ser um núcleo multiprofissional e interdisciplinar, pois se constitui como um paradigma da realidade e de interpretações e intervenções na saúde ${ }^{6}$.

Nesse sentido, o núcleo de SC instituído em todos os cursos na FMABC se apresenta como articulador e transversal nos saberes e práticas da formação na instituição, e de encontros disciplinares e multiprofissionais para a comunicação efetiva, crítica e sensível com a realidade.

[...] trata-se de compreender que o progresso do conhecimento não se dá apenas pela especialização crescente, como estávamos 
habituados a pensar. A Ciência começa a aparecer como um processo que exige também um olhar transversal. Há que olhar para o lado para ver outras coisas, ocultas a um observador rigidamente disciplinar ${ }^{8}$.

A SC também vai nos apontando caminhos e estratégias para a eficiência das interpretações e intervenções nas demandas evocadas pela realidade, no que dizem respeito à saúde e suas interfaces com as demandas sociais.

Dentro de um pensamento dialético a saúde coletiva seria um pedaço do campo da saúde. Valendo-se de imagens, talvez poder-se-ia projetar o campo da saúde como uma matriz em que a saúde coletiva fosse uma parte, em distintos planos de inserção. Desses, pelo menos dois são comentados neste artigo: a saúde coletiva, como movimento intelectual e moral; e a saúde coletiva como um núcleo, uma concentração nuclear de saberes e práticas. Um núcleo co-produzido por miríades de inter-relações com o campo e, ao mesmo tempo, um núcleo co-produtor desse mesmo campo ${ }^{6}$.

Desta forma, a extensão universitária como um eixo do tripé indissociado do ensino-pesquisa-extensão apresenta-se como uma potente estratégia, e eficiente, para atender de forma comunicativa as demandas da realidade no campo da saúde.

[...] a extensão universitária se caracteriza como um campo de práticas comunicativas entre IES e contexto sócio comunitário, uma relação mútua e dialógica entre diversos atores, gerando ações concretas e contextualizadas numa dada realidade social, permitindo o engajamento dos atores nas transformações de suas questões sociais ${ }^{9}$.

É possível destacarmos que no campo da extensão universitária, transversalizada pela SC, há um processo de instrumentalização da interdisciplinaridade. Queremos aqui posicionar e demarcar um conjunto de formas e dispositivos que acionem a apreensão da realidade crítica e sensível, dos agentes da IES e do contexto sociocomunitário, à qual chamamos de ensinagem.

Ensinagem é compreendida como um conjunto de estratégias, técnicas e ferramentas no qual o professor ativamente engajado e articulado no eixo ensino-pesquisa-extensão irá facilitar a sua comunicação e dos estudantes com a população que demanda questões sociais e de saúde.

Para isso, as estratégias funcionam como estruturas de pensamento e visão de mundo do professor sobre a realidade que, de forma complexa, crítica e sensível, organiza e articula encontros, formas de pensar conceituações que impliquem e expressem a linguagem local e científica, e que das linguagens construídas e apreendidas possam ser pensadas técnicas e tecnologias de intervenção. Para tanto, essas técnicas serão conduzidas e materializadas por ferramentas/recursos produzidos entre o contexto local e científico-dialógico, que pode ir do direito social e individual à intervenção propriamente dita da clínica em saúde centrada no corpo.

Será tão mais eficiente a produção e articulação da ensinagem que leve em conta essa dialogicidade: local e científica, micro e macroestrural. Aqui, sob o viés da complexidade de Morin, não há sentidos operacionais para a dicotomização e polarização, há um esforço para a produção dialógica e, portanto, feita por pares, não só da produção local dos agentes sociocomunitários e nem da instituição científica da academia, mas sim do processo constante dos pares. E com isso se faz importante uma condução, para que esse processo de efetive.

A dialogicidade, nos processos de atividades de extensão universitária, pode ser compreendida também como "participação ativa", que é o engajamento ativo de todos os agentes envolvidos num contexto de saber e práticas em saúde?.

A SC, em sua própria constituição, opera como um núcleo determinado pelo processo de participação, em que saber e prática de intervenção se fazem em uma produção de compreensões e acordos para a ação das mudanças das barreiras e dos determinantes que impedem a qualidade de vida da população. Sendo uma co-produção, pois há criadores e criação e criaturas envolvidos ativamente, um modificando o outro e, portanto, alterando as próprias estruturas da $\mathrm{SC}^{6}$.

A proposta que aqui se apresenta é de repensar a Saúde Coletiva filiando-se aquelas escolas filosóficas que sustentam a existência da relação dialética entre o pensar e o agir, entre o homem e o mundo, e entre os próprios homens, entre ser e não ser, ao mesmo tempo. Pensar criador e criaturas embolados, todo o tempo, um ente produzido por ele e por outros ${ }^{6}$.

O posicionamento da ensinagem como uma possibilidade instrumental para operacionalizar a SC nas atividades de extensão universitária é uma tentativa de potencializar a interdisciplinaridade e garanti-la como ação dialógica de reduzir o lugar social de objeto e marginalização das pessoas, seja da população que faz uso dos produtos acadêmicos (tecnologias, teorias, etc.), como dos próprios agentes da academia, que cada vez mais são conduzidos, ora cegos, ora lúcidos, para o jogo perverso da ciência como um campo tecnicista, positivista e competitivo.

Ainda na perspectiva do núcleo de SC proposto dessa forma de operacionalização, diversas formações no campo da saúde deveriam incorporar elementos desse núcleo ${ }^{6}$. Em indagações o autor refere:

[...] todas as profissões de saúde, as nucleadas na clínica ou na reabilitação ou no cuidado, todas, em alguma medida, deveriam incorporar em sua formação e em sua prática elementos da saúde coletiva. [...] Assim, a saúde mental, a neurologia, a saúde da criança, dentre outras áreas, iriam se transformando também em consequência de aportes oriundos da saúde pública. Nessa perspectiva, a missão da saúde coletiva seria a de influenciar a 
transformação de saberes e práticas de outros agentes, contribuindo para mudanças do modelo de atenção e da lógica com que funcionam os serviços de saúde em geral ${ }^{6}$.

Nesse sentido, as experiências de extensão, na FMABC, garantem o tripé ensino, pesquisa e extensão e se somam como parte fundamental do processo de formação profissional, pois colocam estudantes e professores numa relação privilegiada, primeiro entre si, na preparação e desenvolvimento das atividades, mas sobretudo numa relação privilegiada com a comunidade na qual se inserem, não como detentores de um saber que resolve todos os problemas, mas como articuladores de possibilidades e estratégias de ação.

Alunos e professores se aproximam das comunidades para conhecê-las e reconhecê-las, para então fazer proposições que façam sentido e que tenham significados para aquela população, naquele momento específico da vida, mas que ao mesmo tempo os instrumentalize para reconhecer necessidades de mudanças e reorganizações futuras. Isso só é possível porque cada aluno coloca em comum as especificidades de sua formação, buscando reconhecer a sua própria importância, mas também reconhecendo as contribuições das outras especificidades, ou seja, reconhecendo a sua especialidade e o seu lugar no campo da saúde.

Ora, se a interdisciplinaridade é aquilo que articula, que está em inter-relação e, portanto, estabelece entre as disciplinas uma ação recíproca $^{8}$, e complexidade é aquilo que é tecido junto ${ }^{1}$, então acreditamos que a ação interdisciplinar preconiza o pensamento complexo.

Só é possível desenvolver ações de reciprocidade entre as disciplinas se formos capazes de olhá-las de longe, para reconhecê-las como partes de uma única rede, e ao nos aproximarmos de cada uma delas, observarmos os pontos de conexão, de aproximação, de inter-relação, e para isso é preciso treinarmos a ética da compreensão.

\section{REFERÊNCIAS}

1. Morin E. Introdução ao pensamento complexo. Tradução: Eliana Lisboa. $4^{a}$ ed. Porto Alegre: Sulina; 2011.

2. Segre M, Ferraz FC. O conceito de saúde. Rev Saúde Pública. 1997;31(5):538-42 http://dx.doi.org/10.1590/S0034-89101997000600016

3. Ruas TCB. Ações ancoradas na realidade social em saúde infantil: análise das narrativas, dos processos reflexivos e da prática de alunos em terapia ocupacional. Tese (Doutorado) - Faculdade de Medicina do ABC, Santo André, 2014.

4. Herzlich C. Saúde e doença no início do século XXI: entre a experiência privada e a esfera pública. Physis Rev Saúde Coletiva. 2004;14(2):383-94.

http://dx.doi.org/10.1590/S0103-73312004000200011

5. Morin E. Cabeça bem feita: repensar a reforma, reformar o pensamento. Tradução: Eloá Jacobina. $21^{a}$ ed. Rio de Janeiro: Bertrand Brasil; 2014
6. Campos GWS. Saúde pública e saúde coletiva: campos e núcleos de saberes e práticas. Ciênc Saúde Coletiva. 2000;5(2):219-30. http://dx.doi.org/10.1590/S1413-81232000000200002

7. Freire P. Cartas a Cristina: reflexões sobre a minha vida e minha praxis. Rio de Janeiro: Editora Paz; 2013.

8. Pombo O. Interdisciplinaridade e integração dos saberes. Liinc Rev. 2005;1(1):3-15

9. Correia RL, Akerman M. Desenvolvimento local participativo, rede social de suporte e ocupação humana: relato de experiência em projeto de extensão. Rev Ter Ocup Univ São Paulo. 2015;26(1):159-65. http://dx.doi.org/10.11606/issn.2238-6149.v26i1p159-165

10. Luz MT. Complexidade do Campo da Saúde Coletiva: multidisciplinaridade, interdisciplinaridade, e transdisciplinaridade de saberes e práticas: análise sócio-histórica de uma trajetória paradigmática. Saúde Soc. 2009;18(2):304-11. http://dx.doi.org/10.1590/S0104-12902009000200013 